\title{
CARACTERIZAÇÃO PETROGRÁFICA DE BRECHAS VULCÂNICAS NO COMPLEXO ALCALINO DE TUNAS, PR
}

\author{
ELEONORA M.G. VASCONCELLOS* \& CELSO B. GOMES**
}

\begin{abstract}
PETROGRAPHIC CHARACTERIZATION OF VOLCANIC BRECCIAS OF THE TUNAS ALKALINE COMPLEX, PR. The Tunas alkaline complex, covering an area of approximately $22 \mathrm{~km}^{2}$, consists largely of intrusive rock types, the most common lithologies being syenites and alkali syenites. Subordinately, there occur diorites, monzodiorites, gabbros and monzogabbros; small, late "syenitic" (trachyte, microsyenite, bostonite) dikes are also found. About $10 \%$ of the Complex is made up of volcanic breccias in seven different occurrences, four lying in the northwestern sector of the massif (Lajeado 1, Lajeado 2, Lajeado 3, Lajeado 4) and three at its center (Arroio Barro Vermelho, Antena, Barro Vermelho). In addition to these rocks, plutonic breccias (cataclasites and agmatites) have also been noted in a few places. The volcanic breccias show clasts, varying in composition and size, partially or entirely surrounded by a pyroxene-feldspathic (tuffisitic) matrix. Clast composition includes the following constituents: accessory (alkaline rocks: syenite, trachyte, bostonite), accidental (Precambrian country rocks: phyllite, quartzite, metabasite etc.) and essential components (feldspar, pyroxene and biotite phenocrysts). On the basis of its composition and mode of occurrence, the Tunas breccias are considered to be polymictic, and classified as the intrusive fill of volcanic conduits. Texturally, they are mainly matrix-supported and clast-matrix supported and, to a lesser extent, clastsupported.
\end{abstract}

Keywords: Alkaline rocks, breccias, Tunas alkaline complex, Paraná, Brazil.

\begin{abstract}
RESUMO O Complexo Alcalino de Tunas, ocupando área aproximada de $22 \mathrm{~km}^{2}$, é constituído dominantemente de litologias intrusivas, com sienitos e sienitos alcalinos aparecendo como as variedades mais comuns. De modo subordinado, ocorrem dioritos, monzodioritos, gabros e monzogabros, além de pequenos diques de rochas "sieníticas" (traquito, microssienito, bostonito). Cerca de $10 \%$ do complexo consiste em brechas vulcânicas, representando sete ocorrências distintas, quatro localizadas na sua porção noroeste (Lajeado 1, Lajeado 2, Lajeado 3, Lajeado 4) e três (Arroio Barro Vermelho, Antena, Barro Vermelho) na central. Além dessas rochas, reconhece-se também, em alguns lugares, a presença de brechas de origem plutônica (cataclasitos e agmatitos). As brechas vulcânicas contêm clastos de composição e forma variadas, que se apresentam envolvidos, parcial ou totalmente, por uma matriz tufisítica de natureza, em geral, piroxênio-feldspática. Quanto à natureza, os clastos são descritos como do tipo acessório (rochas alcalinas do complexo: sienito, traquito, bostonito), acidental (material pré-cambriano encaixante: filito, quartzito, metabasito etc.) e essencial (fenocristais de feldspato, piroxênio e biotita). Com base na composição e modo de ocorrência, as brechas de Tunas são ditas polimíticas e enquadradas como intrusivas (tufisíticas) de conduto. Texturalmente, são classificadas como suportadas por matrix, por matriz e clastos e, mais raramente, por clastos.
\end{abstract}

Palavras-chaves: Rochas alcalinas, brecha, Complexo Alcalino de Tunas, Paraná, Brasil.

INTRODUCÃ̃o O Complexo Alcalino de Tunas localiza-se no município de Bocaiúva do Sul, próximo à localidade homônima, e dista aproximadamente $60 \mathrm{~km}$ da cidade de Curitiba. Seu acesso é feito pela rodovia BR-476, conhecida como "Estrada da Ribeira".

$\mathrm{O}$ corpo cobre área de cerca de $22 \mathrm{~km}^{2}$, dos quais $10 \%$ correspondem a brechas vulcânicas, e apresenta forma alongada para NW-SE.

A ocorrência de rochas alcalinas na região de Tunas foi citada, inicialmente, por Carvalho \& Pinto (1937), tendo, no entanto, as brechas sido objeto de primeiro registro alguns anos mais tarde (Trein et al. 1967). Cordani \& Hasui (1968) forneceram as primeiras idades radiométricas K/Ar para as rochas do complexo (110-70 Ma), enquanto Fuck (1972) investigou-o detalhadamente do ponto de vista geológico e petrográfico. Numa tentativa de agrupar as numerosas rochas alcalinas brasileiras em associações litológicas razoavelmente definidas, Ulbrich \& Gomes (1981) procuraram correlacionar os diversos tipos petrográfico existentes no complexo àqueles encontrados nas ocorrências da Ilha do Monte de Trigo e Ilha de São Sebastião, enquadrando-os numa associação gábrica alcalina, máfica a ultramáfica.

Das pesquisas mais recentes executadas na área, merece citação a de Gomes et al. (1987), que se ocupou da caracterização geoquímica do complexo e da sua interpretação petrológica, para a qual foi sugerida uma formação por crista- lização fracionada a partir de magmas parentais de natureza gábrica alcalina. Adicionalmente, reuniram novas determinações radiométricas de idade $\mathrm{K} / \mathrm{Ar}$, com os dados indicando variação de 62 a $96 \mathrm{Ma}$ e maior concentração de valores no intervalo 80-90 Ma. A idade média calculada, 82,2 Ma, mostrase similar àquela, igualmente obtida por esses autores, com o emprego do método $\mathrm{Rb} / \mathrm{Sr}(80,5 \mathrm{Ma})$.

Este trabalho baseia-se no levantamento da intrusão alcalina feito por Vasconcellos (1991) e voltado, sobretudo, para as ocorrências de brechas vulcânicas. Ele tem como objetivo principal a caracterização e a descrição petrográfica desse tipo de material, que, não obstante, presente em diversas ocorrências alcalinas do país (p.ex., Itaúna, Lages, Morro Redondo) tem despertado pouca atenção por parte dos pesquisadores brasileiros.

GEOLOGIA LOCAL Como rochas encaixantes, o complexo de Tunas apresenta, na sua porção oeste, filitos, quartzitos, mármores e metabasitos da Formação Votuverava do Grupo Açunguí; na sua parte leste, quartzitos, mármores e metabásicas da Formação Perau, além de gnaisses e xistos do Complexo Apiaí Mirim, ambas unidades pertencentes ao Grupo Setuva (Fig. 1). Ele corta, ainda, diques de diabásio, de direção NWSE e idade Mesozóica, da Formação Serra Geral do Grupo São Bento, que ocorrem por toda a área penetrando as rochas das Formações Votuverava e Perau.

\footnotetext{
* Departamento de Geologia, Centro Politécnico, Universidade Federal do Paraná, Caixa Postal 19001, CEP 81531-970, Curitiba, PR, Brasil

** Instituto de Geociências, Universidade de São Paulo, Caixa Postal 20899, CEP 01498-970, São Paulo, SP, Brasil
} 


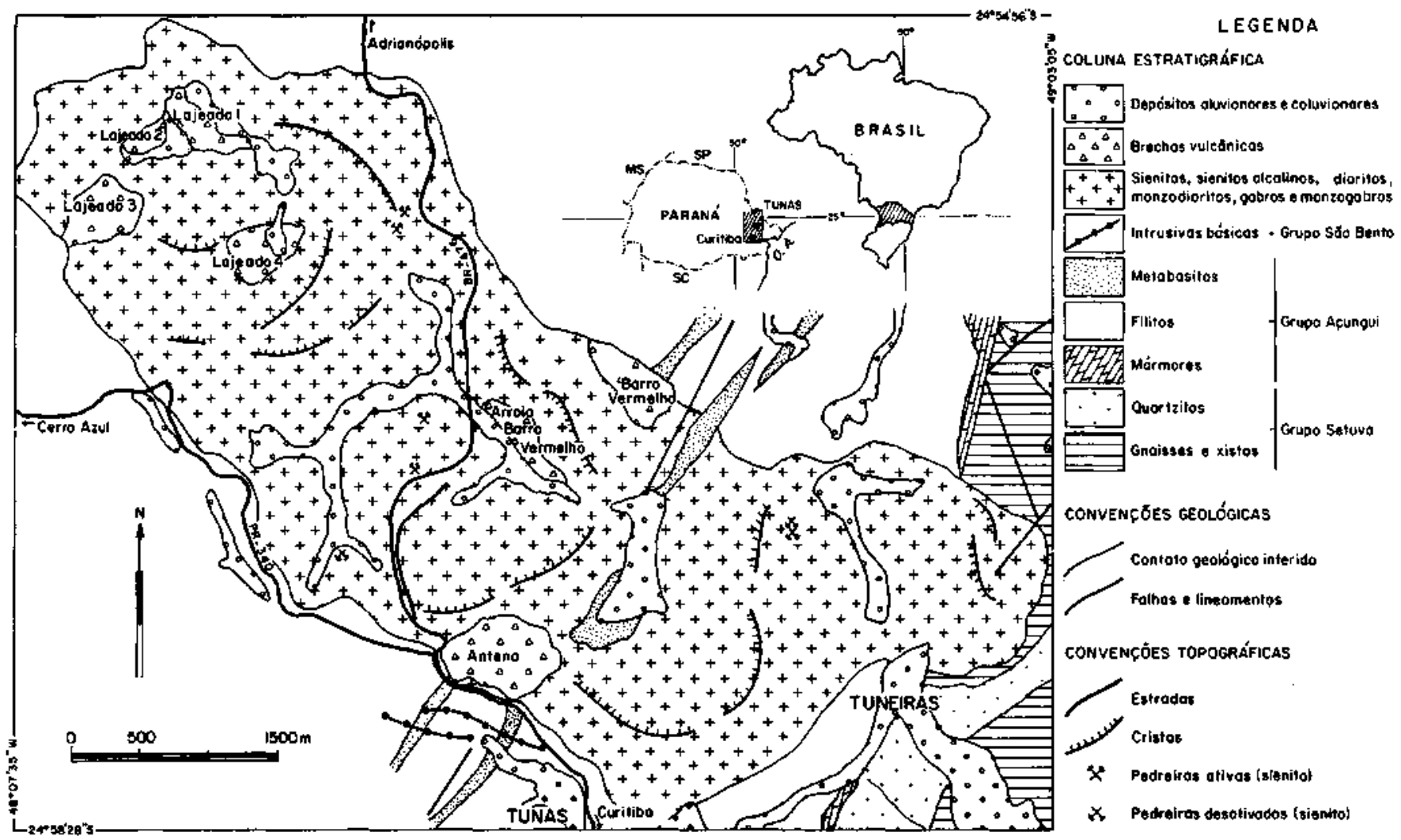

Figura 1 - Mapa geológico do Complexo Alcalino de Tunas, PR (segundo Vasconcellos 1991; simplificado e modificado de Fuck 1972 e Gomes et al. 1987, particularmente, no tocante à área de ocorrência das brechas vulcânicas)

Figure 1 - Geological map of the Tunas, PR, alkaline complex (after Vasconcellos 1991; simplified and modified after Fuck 1972 and Gomes et al. 1987, especially regarding the outcrop area of vulcanic breccias)

A parte sul da intrusão é afetada pela Falha da Lancinha, enquanto a norte pela Falha de Morro Agudo. Segundo Fiori (1985), a reativação da Falha Lancinha deu-se a partir do Mesozóico e, muito possivelmente, o processo atingiu também o corpo alcaüno, uma vez que ele se acha recortado por lineamentos de direção NE-SW, estendendo-se pelas formações précambrianas adjacentes.

O complexo de Tunas é constituído em sua maior parte por rochas intrusivas plutônicas, com as variedades hipoabissais alcançando pequena expressão. As plutônicas têm como tipos mais comuns sienitos e sienitos alcalinos; subordinadamente, estão presentes dioritos, monzodioritos, gabros e monzogabros. As manifestações extrusivas parecem se restringir às ocorrências de brechas. Além disso, foram também reconhecidos veios pegmatóides (rochas portadoras de megacristais de feldspato alcalino e encontradas, principalmente, cortando as variedades sieníticas) e pequenas ocorrências de brechas plutônicas, cataclasitos e agmatitos (nomenclatura segundo Ulbrich 1986). As primeiras situam-se nas bordas dos corpos de brechas vulcânicas ou nas proximidades dos lineamentos de direção NE-SW e as segundas nos contatos do maciço com as rochas metassedimentares regionais. Os agmatitos contêm, em geral, mais de $25 \%$ de clastos, angulosos, de material encaixante (filito, quartzito) envolvidos por uma matriz de natureza sienítica a monzodiorítica.

Gabros e monzogabros afloram, isoladamente, em pequena área, inferior a $0,5 \mathrm{~km}^{2}$, situada ao norte da localidade de Tuneiras, ou então, aparecem associados a dioritos e monzodioritos. Em geral, são rochas de granulação grossa, cor cinza-escuro, e compostas de ripas de plagioclásio de natureza labra-dorítica e minerais máficos. Estes acham-se representados por piroxênio e biotita, fases mais comuns, além de anfibólio e olivina faialítica. Subordinadamente, ocorre feldspato alcalino, interstitial. Como acessórios estão presentes apatita e opacos.
Dioritos e monzodioritos ocorrem, principalmente, ao longo do Arroio Barro Vermelho e afluentes, na porção oeste do complexo. Destacam-se pela sua coloração esbranquiçada, textura ineqüigranular, granulação média a grossa e presença de grande quantidade de biotita lamelar de dimensões centimétricas. Mineralogicamente, consistem em plagioclásio de composição andesínica, feldspato alcalino, piroxênio augítico, anfibólio e olivina faialítica. Apatita e opacos são os acessórios mais freqüentes.

E também comum nessas rochas a presença de grandes xenólitos, angulosos, de material máfico, ou então, arredondados, de natureza quartzítica. O seu tamanho é variável, passando de poucos centímetros a alguns metros.

Sienitos e sienitos alcalinos ocupam aproximadamente $60 \%$ do complexo e têm suas melhores exposições ao longo da rodovia BR-476, onde vêm sendo explorados comercialmente como pedra ornamental. Quando frescas, as rochas são de coloração esverdeada ou, menos comumente, esbranquiçada. A granulação varia de média a grossa e a estrutura, em geral, se mostra maciça. Constituem-se essencialmente de feldspato alcaüno (80-100\% da moda), ocorrendo de forma subordinada plagioclásio, de composição albita até andesina, piroxênio augítico a egirina-augita, biotita, anfibólio, olivina faialítica e nefelina ou quartzo. Como acessórios estão presentes apatita e zircão.

Diques alcalinos formam pequenos corpos cortando principalmente rochas sieníticas e, em menor quantidade, dioríticas a monzodioríticas. Exibem espessuras centimétricas, coloração cinza-claro e cinza-esverdeado e granulação fina. Á textura é tipicamente traquítica, como definida pela orientação dos cristais ripiformes de feldspato alcalino. Petrograficamente, distinguem-se traquitos, microssienitos e bostonitos. A mineralogia indica a presença dominante de feldspato alcalino, aparecendo, subordinadamente, plagioclásio albítico, piroxênio de natureza 
egirina-augita passando a anfibólio, e apatita como acessório.

Brechas vulcânicas estão representadas por sete ocorrências distintas, distribuídas pelo interior do complexo. Quatro delas concentram-se na região de Lajeado, porção NW do corpo, enquanto as demais situam-se mais na sua parte central: uma ao longo do Arroio Barro Vermelho, outra na confluência da rodovia BR-476 com a estrada que leva à localidade de Cerro Azul, junto à antena da rede de eletricidade de Tunas, e uma terceira nas imediações do lugarejo Barro Vermelho.

Com base em Vasconcellos (1991) e para facilidade de descrição, essas ocorrências serão designadas, respectivamente como: Lajeado 1, Lajeado 2, Lajeado 3, Lajeado 4, Arroio Barro Vermelho, Antena e Barro Vermelho (Fig. 1).

\section{ASPECTOS PETROGRÁFICOS DAS BRECHAS}

Lajeado 1 As brechas dessa ocorrência formam um corpo alongado na direção NW-SE, estendendo-se por cerca de $750 \mathrm{~m}$ de comprimento e 50-250 m de largura. Ali se distinguem dois tipos de rocha: o primeiro exibe matriz de coloração escura e textura afanítica; o segundo, coloração mais clara, granulação fina e textura traquítica. Em ambos os casos, a matriz encontra-se envolvida por clastos angulosos a arredondados, tubulares a equidimensionais, de dimensões milimétricas a centimétricas, e apresentando composição extremamente variá- vel, por vezes de difícil caracterização microscópica.

Ao microscópio, observa-se que a matriz possui granulação fina a muito fina, tornando-se mesmo Criptocristalina ou ainda vítrea. Mineralogicamente, identifica-se a presença de feldspato alcalino, de ocorrência intersticial ou como fenocristais xenomórficos, albita, pirpxênio esverdeado na forma de agregados aciculares, e biotita castanha; apatita idiomórfica é o principal acessório (Tab. 1). Ainda que seja difícil determinar a porcentagem modal desses minerais tem-se que feldspato alcalino e piroxênio ocorrem em maior proporção.

Como clastos, reconhecem-se fragmentos de rochas constituintes do maciço, clastos acessórios (traquito, microssienito e sienito), e do material encaixante, clastos acidentais (metabasito, piroxenito, serpentinito, mármore); adicionalmente, fragmentos de minerais (fenocristais de feldspato e de biotita), os chamados clastos essenciais (Tab. 2).

Em geral, os contatos entre os clastos e a matriz são nítidos. Contudo, no caso particular dos clastos de traquito dispersos em matriz traquítica, eles se mostram difusos.

Pela classificação de Ulbrich (1986), essas brechas são classificadas como polimíticas, com textura suportada pela matriz.

Lajeado 2 Representa um pequeno corpo, com cerca de $370 \mathrm{~m}$ por $100 \mathrm{~m}$, aflorando em grandes lajes junto a um

Tabela 1 - Características mineralógicas e texturais da matriz das brechas vulcânicas de Tunas Table 1 - Mineralogical and textural characteristics of the Tunas volcanic breccia matrix

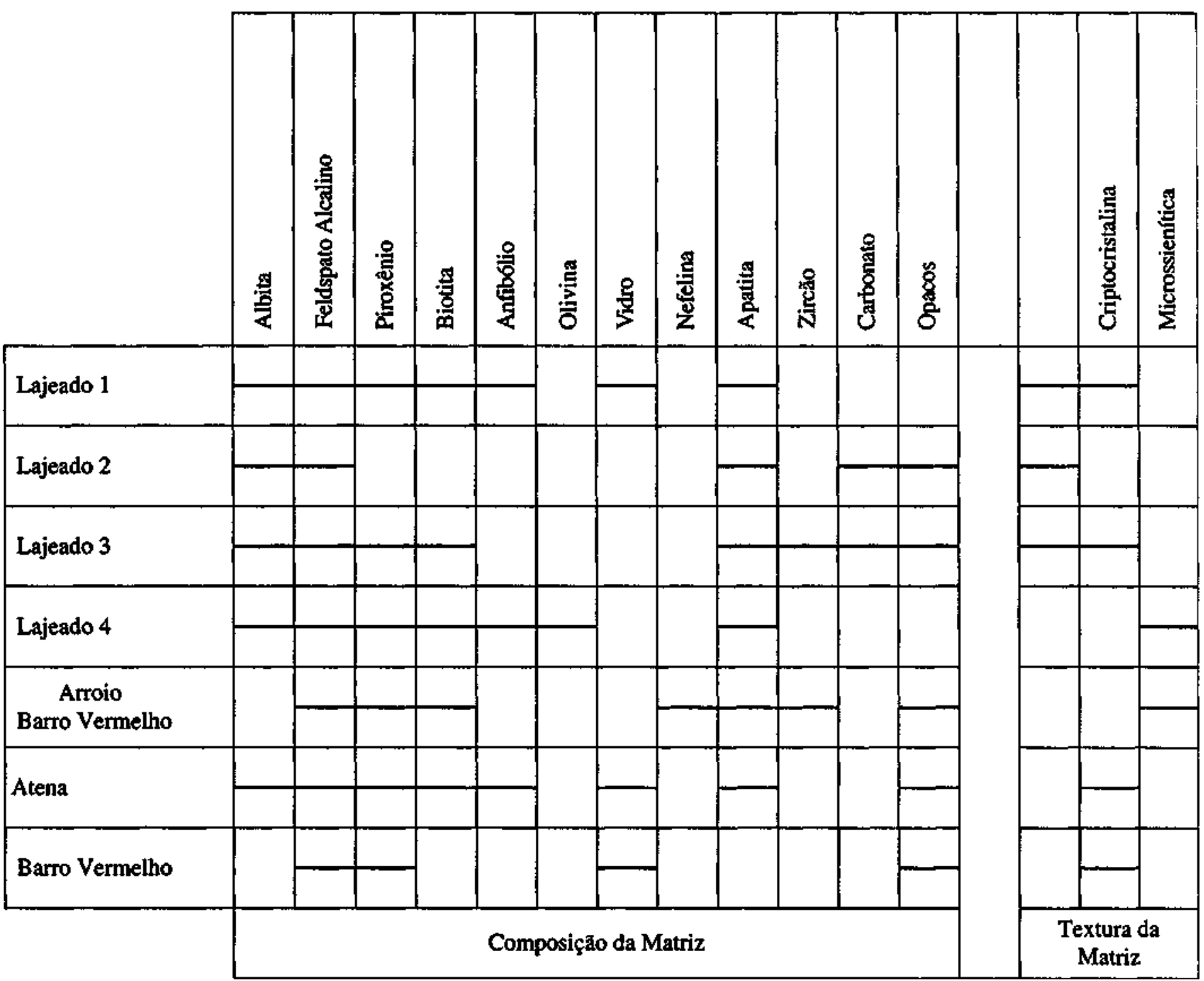


Tabela 2 - Composição dos clastos das brechas vulcânicas de Tunas

Table 2 - Clast composition of the Tunas volcanic breccias

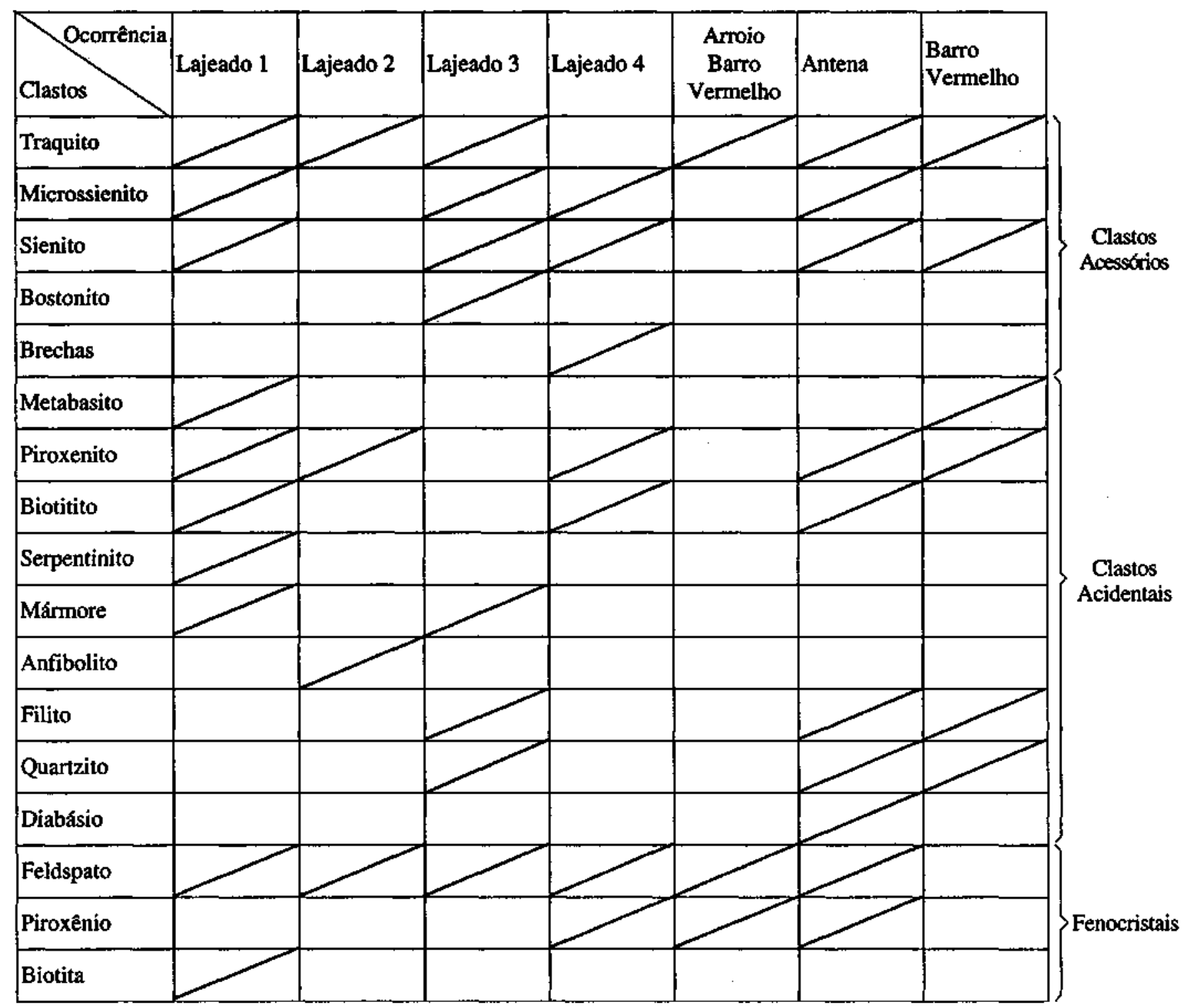

córrego drenando a porção NW do complexo. As brechas presentes são de granulação muito fina, com a matriz se confundindo com os clastos. Relativamente às anteriores, distinguem-se pela coloração mais clara (cinza-claro esverdeado), maior dificuldade para individualização dos clastos em amostras de mão e grande riqueza em carbonates.

$\mathrm{O}$ exame microscópico da matriz revela a presença dominante de albita, por vezes ripiforme e incipientemente orientada em estrutura de fluxo, feldspato alcalino intersticial e quantidade expressiva (em torno de 30\%) de carbonates, na forma de agregados finos. Essas rochas contêm ainda opacos, espalhados por toda a matriz, e apatita como principais acessórios (Tab. 1).

A natureza dos clastos é também variável, com os três tipos fazendo-se representar: acessórios (traquito), acidentais (piroxenito, anfibolito) e essenciais (fenocristais de feldspato) (Tab. 2).

Quanto à classificação, elas se comportam como as anteriores.

Lajeado 3 Esta área de ocorrência inclui brechas formadas no contato do maciço com rochas encaixantes da Formação Votuverava. Elas correspondem a um corpo arredondado de cerca de 300 m de diâmetro, associado, em parte, a metassedi- mentos argilosos (filitos), que exibem, localmente, evidências nítidas de recristalização e vitrificação.

Quando comparadas às anteriores, elas se caracterizam pela maior quantidade de clastos e pouca ou nenhuma matriz, formas (angulosas a subarredondadas, equidimensionais a tabulares) e dimensões (poucos milímetros até aproximadamente $30 \mathrm{~cm}$ ) variadas, além de composição heterogênea. A matriz é afanítica, chegando, por vezes, quase a criptocristalina, e de coloração cinza escuro. Ocorre subordinadamente aos clastos, preechendo os espaços entre eles. Nota-se também a existência de bordas de reação, levando à intensa recristalização dos clastos.

Ao microscópio, e quando bem cristalizada, é possível definir-se na matriz a presença de albita ripiforme ligeiramente orientada, feldspato alcalino xenomórfico, além de piroxênio, augita a egirina-augita, na forma de agregados finos ou como cristais hipidiomórficos. Biotita, carbonates e opacos estão presentes em menor concentração, enquanto apatita e zircão correspondem aos principais acessórios (Tab. 1).

Quanto aos clastos, eles podem ser acessórios (traquito, microssienito, sienito, bostonito), acidentais (mármore, filito, quartzito; com predominância do primeiro tipo) e essenciais (fenocristais de feldspato). 
Segundo o esquema de Ulbrich (1986), essas brechas são classificadas como polimíticas, com textura suportada por ciastos ou por clastos e matriz.

Lajeado 4 Essa ocorrência corresponde a um corpo arredondado, ligeiramente alongado para NE, e com cerca de 300 a $500 \mathrm{~m}$ de diâmetro. As brechas distínguem-se das demais por possuírem matriz melhor cristalizada e clastos de brechas mais antigas. A coloração da matriz é cinza-escuro, contrastando com a da matriz das brechas mais antigas, em geral cinzaesbranquiçado. Os fragmentos exibem dimensões milimétricas a centímétricas, com tamanho máximo de $25 \mathrm{~cm}$ de comprimento, e formas as mais variadas (angulosas a subarredondadas, equidimensionais a tabulares).

Microscopicamente, são rochas constituídas de feldspato alcalino xenomórfico, incipientemente alterado e na forma de agregados, albita, biotita (cerca de 30\%), piroxênio de composição augítica a egirina-augítíca e, em menor quantidade, anfibólio e olivina alterando para silicates, além de apatita como acessório (Tab. I). Em algumas amostras, os minerais encontram-se orientados, sugerindo possível estrutura de fluxo.

Os clastos são bastante variados, predominando contudo os chamados essenciais (fenocristais de feldspato e piroxênio); adicionalmente, estão presentes clastos acessórios (microssienito, sienito, brechas) e acidentais (piroxenito, biotitito) (Tab. 2). Os clastos formados a partir de brechas mais antigas apresentam matriz semelhante à das brechas que os envolvem.

Quanto à classificação segundo Ulbrich (1986), elas são definidas como do tipo polimítico, com textura suportada pela matriz; não existe contato entre os clastos.

Arrolo Barro Vermelho Descrita por Fuck (1972) e Hara \& Silva (1982), essa ocorrência forma um corpo alongado, com quase $1 \mathrm{~km}$ de comprimento e $200 \mathrm{~m}$ de largura, junto à porção central do complexo. As brechas apresentam matriz inequigranular e clastos de pequenas dimensões.

Ao microscópio, a matriz é de granulação média, além de constituída por feldspato alcalino ripiforme, intensamente alterado, e agregados finos de piroxênio augítico e biotita, em geral associado a opacos. Estes aparecem também na forma de cristais maiores (magnetita) com textura esquelética. Subordinadamente, ocorre nefelina idiomórfica; na condição de acessórios, foram reconhecidos apatita e zircão (Tab. 1).

Os clastos, de pequenas dimensões e formas variadas, são do tipo acessório (traquito) e essencial (fenocristais de feldspato e piroxênio).

Essas brechas são também de natureza polimítica, com textura suportada por matriz.

Antena Representa a maior ocorrência de brechas do complexo, correspondendo a um corpo alongado segundo E-W, com aproximadamente $1 \mathrm{~km}$ de comprimento por $600 \mathrm{~m}$ de largura. Os afloramentos são abundantes, em cortes de estrada ou em meia encosta, e quase sempre na forma de grandes blocos arredondados. Essas rochas acham-se em contato, raramente nítido, com sienitos e sienitos alcalinos, no interior do maciço, e filitos e metabasitos da Formação Votuverava, na sua porção externa. Nessa ocorrência distinguemse também afloramentos de cataclasito, com os limites das brechas mostrando-se em geral bruscos e claramente visíveis ao longo dos cortes de estradas à trilhas recortando a área.

As brechas são constituídas por clastos milimétricos a centimétricos, angulosos a arredondados e de composição variada, envolvidos por uma matriz fina a muito fina (criptocristalina) de coloração cinza-escura. Em geral, a granulação da matriz é mais fina nas proximidades dos clastos.

Em lâmina delgada, verifica-se que a matriz consiste em feldspato alcalino, albita intersticial, piroxênio, biotita, opacos e, subordinadamente, anfibólio; apatita é o principal acessório
(Tab. 1). Por vezes, identifica-se também a presença de material isótropo (vidro vulcânico) de ocorrência intersticial.

A natureza dos clastos é muito diversificada, sendo reconhecidos clastos acessórios (traquito, microssienito, sienito), acidentais (piroxenito, biotitito, filito, quartzito, além de uma amostra de diabásio) e essenciais (fenocristais de feldspato e piroxênio) (Tab. 2). Comparativamente às demais ocorrências de brechas, nota-se aqui uma maior quantidade de clastos de quartzito.

Nessas brechas descreve-se, ainda, a presença de pequenas cavidades, arredondadas ou alongadas, preenchidas por minerais diversos (olivina, serpentina, piroxênio, biotita, feldspato), ao lado ou não de material vítreo.

Texturalmente, essas rochas são, a exemplo das demais e excluídas as de Lajeado 3, enquadradadas no tipo suportado por matriz. Quanto à composição dos fragmentos, elas classificamse também como polimíticas.

Barro Vermelho No limite norte do complexo, junto à localidade de Barro Vermelho, ocorrem brechas na forma de um corpo alongado para NW, estendendo-se por cerca de $700 \mathrm{~m}$ e $300 \mathrm{~m}$ de largura. Ele acha-se em contato com metassedimentos da Formação Votuverava e contém grande quantidade de clastos maiores, arredondados a subarredondados, além de presentes em pequena quantidade.

Em lâmina delgada, observa-se que a matriz é de difícil definição, podendo chegar a criptocristalina e, em geral, pouco abundante. Mineralogicamente, compõe-se de feldspato alcalino, piroxênio augítico na forma de agregados finos ou preenchendo fraturas nos clastos, opacos e, em pequena quantidade, vidro vulcânico (Tab. 1).

Os clastos predominantes são do tipo acidental, notadamente de filito e, em menor proporção de quartzito, metabasito e piroxenito. Como clastos acessórios ocorrem traquito e sienito (Tab. 2). Ao contrário das demais, nessas brechas não se observam clastos de fenocristais.

Com base no esquema de Ulbrich (1986), as brechas de Barro Vermelho são tidas como polimíticas, com textura suportada por clastos ou por clastos e matriz.

CONSIDERAÇÕES GERAIS Pela classificação de Ulbrich (1986), brechas ígneas são rochas constituídas de clastos angulosos a arredondados, de diâmetro superior a $2 \mathrm{~mm}$, e originadas pela ação de processos ígneos ou que acompanham esses processos. Elas incluem tanto as brechas vulcânicas, como as subvulcânicas e plutônicas.

As classificações mais antigas de brechas vulcânicas baseavam-se no tamanho dos fragmentos piroclásticos, à semelhança do adotado no estudo das brechas sedimentares (Wentworth \& Williams 1932 in Lajoie 1984), ou então, se fixavam nos processos formadores dessas rochas (Fisher 1960, 1961; Wright \& Bowes 1963; Parsons 1969). Ulbrich (1986) discute essas classificações, questionando o seu lado prático, uma vez que elas se alicerçavam basicamente em aspectos genéticos. Propõe, alternativamente, para todas as brechas um novo esquema classificatório levando em consideração o ambiente geológico de colocação desses corpos.

Com base nessa classificação, as brechas de Tunas são consideradas subvulcânicas de conduto, do tipo intrusivo e tufisítica. Subordinadamente, ocorrem também brechas de origem plutônica, distinguindo-se brechas de fricção de borda (cataclasitos) e agmatitos. $\mathrm{O}$ caráter intrusivo das rochas do complexo foi definido a partir da análise comparativa com dados da literatura para ocorrências congêneres associadas às manifestações alcalinas e da descrição de Ulbrich (1986).

Em Tunas, as brechas formam, na superfície, corpos irregulares, de tendência arredondada ou alongada e tamanho variado. A estrutura mais comum é a do tipo maciço e, secundariamente, de fluxo. Texturalmente, essas brechas são suportadas por matriz ou por matriz e clastos; menos comumente, por 
clastos. Os clastos possuem formas e dimensões variadas, além de natureza polimítica, e acham-se envolvidos por matriz fina a criptocristalina tufisítica.

Tentativas de enquadramento dessas rochas com base no tipo de clastos presentes permitem o reconhecimento de três grupos distintos:

1. brechas contendo fragmentos acessórios, acidentais e essenciais (fenocristais). Aqui se inclui a maioria das ocorrências: Lajeado 1, Lajeado 2, Lajeado 3, Lajeado 4 e Antena;

2. brechas portadoras de clastos acessórios e essenciais: Arroio

Barro Vermelho;

3. brechas reunindo apenas clastos acessórios e acidentais:

Barro Vermelho.

Por outro lado, o agrupamento dessas rochas segundo a natureza da matriz possibilita, também, a definição de três tipos diferentes:
1. brechas exibindo matriz traquítica e estrutura de fluxo: Lajeado 1 e Lajeado 2;

2. brechas com matriz granular e de composição microssienítica: Lajeado 4 e Arroio Barro Vermelho;

3. brechas apresentando matriz criptocristalina vitrificada: Lajeado 3, Antena e Barro Vermelho.

Por último, a partir da forma e tamanho dos clastos, é possível caracterizar dois grandes grupos:

1. brechas do interior do complexo, onde predominam fragmentos arredondados e equidimensionais;

2. brechas de borda, onde aparecem mais comumente fragmentos maiores e de formas angulosas e tabulares.

Agradecimentos Estes são devidos à FAPESP (Proc. 90/3692-7) pelo apoio financeiro concedido para a realização deste trabalho.

\section{REFERÊNCIAS BIBLIOGRÁFICAS}

CARVALHO, RR \& PINTO, E.A. 1937. Reconhecimento geológico na Série Assunguy. Boi Serv. Geol Miner, 71:1-29.

CORDANI, U.G. \& HASUI, Y. 1968. Idades K-Ar de rochas alcalinas do Primeiro Planalto do Estado do Paraná. In: CONGR. BRÁS. GEOL., 22. Belo Horizonte, 1968. Anais... Belo Horizonte, SBG. p. 149-153.

FIORI, A.P. 1985. Avaliação preliminar do deslocamento dúctil das falhas de Lancinha e de Morro Agudo no Estado do Paraná. Boi. Parati. Geoc. 36:15-29.

FISHER, R.V. 1960. Classification of volcanic breccias. Geol. Soe. Am. Bull, 71:973-982.

FISHER, R.V. 1961. Proposed classification of volcaniclastic sediments and rocks. Geol Soc. Am. Bull, 72:1409-1414.

FUCK, R.A. 1972. Geologia do Maciço Alcalino de Tunas, Paraná, Brasil São Paulo. 82 p. (Tese de Doutoramento, IG/USP).

GOMES, C.B.; BARBIERI, M.; BECCALUVA, L.; BROTZU, P.; CONTE A.; RUBERTI, E.; SCHEIBE, R; TAMURA, R.M.; TRAVERSA, G. 1987. Petrological and geochemical studies of alkaline rocks from continental Brazil. 2. The Tunas massif, State of Paraná. Geochim. Brasil, 1:201-234.

KARA, S.R \& SILVA, M.E. 1982. Relatório de Graduação da Folha Geológica de Água Clara/parcial leste do Barro Vermelho. Curitiba. 80 p. (Relatório de Graduação, Departamento de Geologia/UFPR).

LAJOffi, J. 1984. Volcaniclastic rocks. In: WALKER, R.G. 2 ed. Fades Models. Canada, Geoscience Canada, p. 39-52. (Reprint, series 1).
PARSONS, W.H. 1969. Criteria for the recognition of volcanic breccias: review. Geol. Soc. Amer. Mem., 155:263-304.

TREIN, E.; MARINI, O.J.; FUCK, R.A. 1967. Rochas alcalinas do Primeiro Planalto do Estado do Paraná. In: BIGARELLA, J.J.; SALAMUNI, R.; PINTO, VM. ed. Geologia do Pré-Devoniano e Intrusi vás Subseqüentes da Porção Ocidental do Estado do Paraná. Boi. P ar an. Geoc., 23-25:325-347.

ULBRICH, H.H.G.J. 1986. As brechas de origem ígnea: revisão e proposta para uma classificacão geológica. Boi IG-USP, 3:1-82. (Ser. Publ. Esp.).

ULBRICH, H.H.GJ. \& GOMES, C.B. 1981. Alkaline rocks from continental Brazil. Earth Sci. Rev., 17:145-154.

VASCONCELLOS, E.M.G. 1991. Investigações Geológicas e Petrológicas das Brechas Vulcânicas do Maciço de Tunas, PR. São Paulo. 128 p. (Dissertação de Mestrado, IG/USP).

WRIGHT, A.E. \& BOWES, D.R. 1963. Classification of volcanic breccias: a discussion. Geol. Soc. Am. Bull, 74:79-86.

MANUSCRITO A733 Recebido em 28 de julho de 1992 Revisão do autor em 25 de agosto de 1992 Revisão aceita em 25 de agosto de 1992 